\title{
The state of breeding birds in Greece: trends, threats, and implications for conservation
}

\author{
DIMITRIOS VAVYLIS ${ }^{1,2 \neq, *}$ (D), ANASTASIOS BOUNAS ${ }^{2,3 *, *}$, \\ GEORGIOS KARRIS ${ }^{4}$ and KOSTAS A. TRIANTIS ${ }^{1}$ \\ ${ }^{1}$ Department of Ecology and Taxonomy, Faculty of Biology, National and Kapodistrian University \\ of Athens, Athens GR-15784, Greece. \\ ${ }^{2}$ Hellenic Ornithological Society/BirdLife Greece, Themistokleous 80, 10681, Athens, Greece. \\ ${ }^{3}$ Department of Biological Applications and Technology, University of Ioannina, Ioannina, 45110, \\ Greece. \\ ${ }^{4}$ Lab of Environmental Physics, Energy and Environmental Biology, Department of Environment, \\ Faculty of Environment, Ionian University, Panagoula, GR-2910o Zakynthos, Greece.
}

fequal contribution

*Authors for correspondence; email:dvavylis@biol.uoa.grEsabounas@cc.uoi.gr

(Received 20 July 2020; revision accepted 22 October 2020)

\section{Summary}

Birds are suffering from steep population declines on a global scale and they are one of the few taxonomic groups for which these declines are well documented by long-term monitoring data. This study provides a synthesis of the status of the breeding birds of Greece. To this aim, we retrieved population size estimates from six sources spanning 22 years (1992-2014) and calculated species' trends in Greece. Using the IUCN Red List assessments for each species we assessed whether ecological traits including habitat and diet preferences were associated with species' trends and conservation status in Europe and determined major threats affecting birds in Greece. Moreover, we assessed the importance of Important Bird \& Biodiversity Areas (IBAs) in terms of declining trigger species. Results showed that almost one fifth of the breeding birds in Greece have declining populations. Raptors were found to be the most threatened group of birds whereas the highest declines by dietary group were observed in scavengers, with $60 \%$ of species showing a decreasing trend. The most common threats were those that cause habitat alteration and degradation as well as more direct effects such as poisoning. Our results suggest that restoration of habitat and ecosystem functions along with the management of protected areas and improvement of legislation should be the main conservation actions undertaken and pinpointed the IBAs where they should be prioritized for implementation. Finally, further research, especially on specific drivers of population change, along with further examination of current and past population trends, will increase the power and accuracy of future regional Red List assessments especially concerning the breeding species for which the country bears the greatest responsibility.

Keywords: bird population trends, conservation priorities, Greece, Important Bird and Biodiversity Areas, IUCN Red List 


\section{Introduction}

Global biodiversity is decreasing at alarming rates (Barnosky et al. 2011, Ceballos et al. 2017). As a result of environmental degradation, habitat loss, invasive species and effects of climate change, more and more species are threatened with extinction (Butchart et al. 2010). Thus, the urgent need to reduce the rates of biodiversity loss has been recognized as a priority environmental concern, resulting in a number of international conventions and agreements. Towards that goal, the International Union for the Conservation of Nature (IUCN) Red List of Threatened Species is undoubtedly the most comprehensive and updated source regarding the global conservation status of animals and plants, highlighting species with the greatest extinction risk, assessing threats and promoting their conservation through management actions and research recommendations (Rodrigues et al. 2006).

Birds are well-known to be suffering steep population declines on a global scale (Butchart et al. 2004, Rosenberg et al. 2019) that could in turn disrupt critical ecosystem services (Şekercioğlu et al. 2004). Birds are excellent indicators of terrestrial and aquatic biodiversity, habitat quality and environmental conditions, and can be used to assess conservation targets (Kati et al. 2004, Mace and Baillie 2007). Their usefulness and reliability as ecological indicators lies mainly in the fact that they are a very widespread and diverse taxonomic group, their ecology is very well-documented with long-term monitoring efforts held in several countries, and since they are usually top predators, they are sensitive to climate and land use changes (e.g. Gregory et al. 2005). For instance, estimating bird trends is key for setting bird conservation priorities (Sutherland et al. 2004), whereas bird trends often reflect population changes in other animal and plant taxa thus providing a better understanding of wider environmental health (e.g. Gregory et al. 2005).

Greece holds an important geographical position, located at the intersection of three continents, Europe, Africa and Asia. In total, 455 bird species have been recorded in Greece, of which 347 species occur regularly (Legakis and Maragou 2009). The country has no endemic species but encompasses the southernmost or westernmost limit of several species' breeding range within the Western Palearctic (Legakis and Maragou 2009). Two species, the Goosander Mergus merganser and the Greylag Goose Anser anser, exhibit isolated breeding populations that are considered to be relict populations that settled in the area after the last glacial maximum (Catsadorakis et al. 2016, Bounas et al. 2018). Moreover, for some species, Greece hosts a major percentage of their global population, e.g. Eleonora's Falcon Falco eleonorae, with more than $80 \%$ of its global population breeding in Greece (Dimalexis et al. 2008).

In the last few decades, ornithology in Greece has undoubtedly flourished, with several studies conducted which mainly dealt with monitoring surveys, bird conservation biology, reproductive biology, habitat use and diet of birds (Kazantzidis 2007), therefore significantly contributing to our current understanding of distribution, numbers and species' ecology. Naturally, increased research and knowledge has led to the implementation of conservation measures for certain threatened species. Several conservation projects have been implemented in the country so far, mainly under the framework of European Commission's LIFE programme, the main funding instrument for nature conservation in the European Union. From its launch in 1992, a total of 81 LIFE Nature projects have been implemented in Greece with 28 of them focused specifically on birds (https://ec. europa.eu/environment/life/project/Projects/index.cfm, accessed on July 2020). Despite all of the abovementioned efforts, there is currently no comprehensive review of the trends, status, threats, and conservation needs of all the bird species breeding in Greece. The main aim of this study is to provide a synthesis of the status of the 246 breeding birds of Greece by compiling available published information including population estimates and IUCN assessments. Thus, we assess the extent of increase or decline for each species and determine whether ecological traits including habitat and dietary preferences are associated with species' trends and conservation status. We also evaluate which Important Bird \& Biodiversity Areas (IBAs) designated in Greece hold the highest number of species and which of these IBAs face the greatest threats. Finally, we determine the threats affecting most of the breeding species in Greece and identify priority actions for conservation and research. Our findings will be a first step towards an integrated approach in setting conservation priorities in a national level. 


\section{Methods}

\section{Data collection}

To compile a contemporary list of the breeding birds of Greece we included 242 of the 244 species that have been reported to have a permanent and regular breeding population in Greece in the late 1990s (Handrinos and Akriotis 1997). The two species excluded were the Red-legged Partridge Alectoris rufa, as the fate of this introduced population is unknown, and Marmora's Warbler Sylvia sarda since previous records in the 1980 are probably a result of misidentification (Handrinos and Akriotis 1997). We also did not consider the Black Francolin Francolinus francolinus, since it has become extinct in the country since the second half of the $19^{\text {th }}$ century (Handrinos and Akriotis 1997). Additionally, four more species, the Short-eared Owl Asio flammeus, Great Bittern Botaurus stellaris, Cattle Egret Bubulcus ibis and Rook Corvus frugilegus were included as breeding species. More specifically, the Short-eared Owl and the Great Bittern were listed as breeding in the most recent Red Data Book of the Threatened Animals of Greece (Legakis and Maragou 2009), while the Cattle Egret and Rook, although irregular breeders in the past, now breed regularly in the country (Kazantzidis et al. 2016). Consequently, we focused on a list of 246 species breeding in Greece.

Population size estimates for all breeding species in Greece were retrieved from six sources spanning 22 years, from 1992 to 2014: i) The first regional Red Data Book of Greece (Karandinos and Paraschi 1992), before the establishment of the modern criteria and categories by IUCN. This is the first publication that estimated extinction risks for the birds of Greece and provided population size data on 48 breeding species, mainly non-passerines. ii) The first ever review of the status and populations of all wild species of birds in Europe at a country level (Tucker and Heath 1994), including 108 breeding species from Greece. We did not include data for 34 of these species for which the population estimates were based on poorly known or no quantitative data. iii) 'The birds of Greece' (Handrinos and Akriotis 1997), the first, and up to now the only complete publication on the status of all bird species of Greece. We extracted population data for all the breeding species of Greece. iv) The 'Birds in Europe 2 ' publication (BirdLife International 2004) that updated the previous version from 1994 and included quantitative data for all species and countries of Europe. Data for all 246 breeding species of Greece were extracted. v) The second regional Red Data Book of Greece (Legakis and Maragou 2009) although the first one using the quantitative criteria of IUCN. In total, 122 species have been assessed and assigned to extinction risk categories, and for 64 of them detailed population data were included. vi) The most recent publication on the status of European birds (BirdLife International 2017) that updated the 2004 publication. Even though it was published in 2017, the majority of the data on population estimates refers to 2013-2014, since they were collated for the publication of European Red List of Birds (BirdLife International 2015). This publication contained population data for 85 breeding species Greece. However, estimates for all 246 breeding species were kindly provided by the Hellenic Ornithological Society/BirdLife Greece for the purposes of this study. Our final dataset, therefore, included population size estimates (as minimum and maximum values) for all 246 breeding species, with 225 of them assessed for at least three distinct points in time (1992, 1994, 1997, 2004, 2009 and 2014; Table S1 in the online supplementary material).

The retrieved population estimates do not come from a single standardized method; therefore, such heterogeneous datasets could provide misleading rates of change for certain species. Both for decreasing and even more so for increasing species, it is challenging in some cases to clarify whether the trend is due to actual changes in abundance (due to successful conservation measures for example) or a change in the method of estimation, or even due to increased survey effort in known or new areas of occurrence (Brouwer et al. 2003, Dimalexis et al. 2008). Thus, overall patterns should be viewed with some degree of caution.

Each one of the species breeding in Greece was assigned to a taxonomic order, to its population trend in Europe (Increasing, Stable, Decreasing, Unknown) and to the IUCN category of extinction 
risk according to BirdLife International (2015). Red List assessments also contain ecological information such as habitat preferences. These are coded against a hierarchical habitat classification scheme, with broad (Level One) habitat types that further include more specific (Level Two) habitats. For each species, we considered classifications that were coded by IUCN as of Major Importance, indicating that the habitat type is an absolute requirement, hereafter as primary habitat (https:// www.iucnredlist.org/resources/habitat-classification-scheme). Furthermore, we classified all species into dietary groups, hereafter 'primary diet', based on data from Wilman et al. (2014) quantifying the dietary contribution of 10 different food categories. Species were assigned a primary diet when they obtained the majority of their resources $(>60 \%$ ) from one of the corresponding food categories while the remaining species were classified as omnivores (Pigot et al. 2016). Similar to habitat preferences, IUCN Red List assessments classify threats, recommended conservation actions and research needs hierarchically with Level One, encompassing Level Two classifications (Salafsky et al. 2008). In each species, we assigned the corresponding threats at Level One except for 'Biological Resource Use' and 'Natural Systems Modifications', which were assigned at Level Two of the classification scheme following McClure et al. (2018), since these broad (Level One) categories represent heterogeneous threat types. We only considered threats coded as having a Low, Medium, and High impact. Recommended conservation actions were assigned at Level One whereas research needs were assigned at Level Two for each species. Finally, we retrieved any breeding bird of Greece that qualifies as an IBA Trigger species, under the relevant criteria (BirdLife International 2014), in any of the 204 IBAs identified in Greece (Portolou et al. 2009, Fric et al. 2012).

\section{Data analysis}

The population trend of each species in Greece was identified by calculating the slope of the least squares regression line between the year and the respective mean population size (mean of minimum and maximum estimates). For the results to be comparable in magnitude among species we standardized the mean population estimates (z-transformation) resulting in standardized slopes (Schielzeth 2010). Standardized slopes were subsequently projected to biologically meaningful values reflecting the percentage rate of change of species' populations per year (Kleinbaum et al. 2013, Sauer et al. 2017). Species with positive or negative slopes showing an overall annual rate of change $>_{1} \%$ were assigned to an 'Increasing' or 'Decreasing' trend respectively. Species with either a slope point estimate of zero or an overall annual rate of change $<1 \%$ were characterized as 'Stable' (van Strien et al. 2001, Vorisek et al. 2008). Species for which population size estimates were not available for at least two points in time, were considered as 'Unknown' trend. Additionally, we calculated the percentage change between the oldest and the most recent population size estimate for each species across years to evaluate the overall largest population increases and declines.

Furthermore, we calculated the percentage of species per taxonomic order and per ecological trait (habitat used, primary diet) within each Red List category and for each direction of population trend both in Greece and in Europe. We performed chi-square tests to examine any statistically significant differences in numbers of threatened or declining species within groups. To determine the threats affecting the declining breeding birds in Greece and identify priority actions for conservation and research we calculated the number of species for which each threat type was listed as well as the number of species with decreasing trends for which each category of conservation action and research needed was recommended by IUCN. Finally, we examined the importance of IBAs for the breeding birds of Greece by calculating the richness of trigger species, and the number of declining trigger species in each IBA. All data manipulation and analyses were performed in R 3.6.2 (R Core Team 2019) and QGIS 2.18 (QGIS Core Team 2016).

\section{Results}

Of the 246 breeding birds of Greece analyzed, 110 species ( $44.7 \%$ ) had positive trends, 87 species $(35.4 \%)$ had stable trends and 46 species (18.7\%) were found to be declining. Three species (1.2\%; 
Table 1 . Top ten species with the greatest changes in their population sizes in Greece along with their European trend and the European IUCN category of extinction risk. Values are presented as percentage change from the oldest to the newest population size estimate (1992 to 2014).

\begin{tabular}{|c|c|c|c|}
\hline Species & $\%$ population change & European trend & IUCN Europe \\
\hline \multicolumn{4}{|l|}{ Decreasing } \\
\hline Chlidonias hybrida & $-97 \cdot 5$ & Increasing & LC \\
\hline Neophron percnopterus & -95.2 & Decreasing & EN \\
\hline Aquila heliaca & -95.0 & Increasing & LC \\
\hline Chlidonias niger & -90.0 & Unknown & LC \\
\hline Ardea purpurea & -85.0 & Decreasing & LC \\
\hline Acrocephalus melanopogon & $-77 \cdot 3$ & Unknown & LC \\
\hline Fringilla coelebs & $-75 \cdot 5$ & Stable & $\mathrm{LC}$ \\
\hline Regulus regulus & -70.0 & Decreasing & LC \\
\hline Emberiza melanocephala & -70.0 & Decreasing & LC \\
\hline Anser anser & -70.0 & Increasing & LC \\
\hline \multicolumn{4}{|l|}{ Increasing } \\
\hline Corvus frugilegus & 99.9 & Decreasing & LC \\
\hline Sturnus vulgaris & 98.6 & Decreasing & LC \\
\hline Cygnus olor & 98.0 & Increasing & LC \\
\hline Bubulcus ibis & $97 \cdot 5$ & Decreasing & $\mathrm{LC}$ \\
\hline Alauda arvensis & 96.5 & Decreasing & LC \\
\hline Clamator glandarius & $95 \cdot 7$ & Increasing & LC \\
\hline Streptopelia decaocto & $95 \cdot 7$ & Increasing & LC \\
\hline Passer montanus & 94.1 & Uncertain & LC \\
\hline Melanocorypha calandra & 93.0 & Decreasing & $\mathrm{LC}$ \\
\hline Tadorna tadorna & 92.6 & Increasing & $\mathrm{LC}$ \\
\hline
\end{tabular}

Black-headed Gull Larus ridibundus, Eurasian Pygmy-owl Glaucidium passerinum and the Wood Warbler Phylloscopus sibilatrix) were assigned an unknown trend. Extreme population declines were observed for the Whiskered Tern Chlidonias hybrida and the Egyptian Vulture Neophron percnopterus with an overall loss of $97.5 \%$ and $95.2 \%$ of their populations respectively between 1992 and 2014. The Imperial Eagle Aquila heliacal and Purple Heron Ardea purpurea also showed declines of great magnitude with values of $95 \%$ and $90 \%$ respectively. Top increasers include Rook Corvus frugilegus (99.9\%), Common Starling Sturnus vulgaris (98.6\%), Mute Swan Cygnus olor (98\%) and Cattle Egret Bubulcus ibis (97.5\%). The top 1o species with the largest population change in Greece are shown in Table 1 . Species showing the highest average annual decline rates during 1992-2014 include the Whiskered Tern (5.1\%), Moustached Acrocephalus melanopogon and Great Reed Acrocephalus arundinaceus Warblers (4.7\% and $4.3 \%$ respectively), and Egyptian Vulture $(3.9 \%)$. On the other hand, the highest average annual increase rates were observed in Collared Dove Streptopelia decaocto (9.6\%) and Pallid Swift Apus pallidus (8.7\%). The 1o species with the highest rate of increase and decrease in Greece are shown in Table 2. Eight species (3.3\%) of the 246 breeding birds of Greece assessed by IUCN, are considered threatened in Europe ('Vulnerable' or 'Endangered') with four more species (1.6\%) classified as 'Near Threatened'. A quarter of the 246 species $(n=63,25.6 \%)$ have declining population trends in Europe, another quarter $(n=62,25.2 \%)$ show increasing population trends, whereas for 75 species $(30.5 \%)$ trends are stable and for the remaining 46 species (18.7\%) the trends are unknown. A comparison of the proportion of threatened or declining species (based on their trend both in Greece and Europe) between taxonomic orders (Figure $\mathrm{S}_{1}$ ), showed no disproportionate declines in Greece (Chisquared $=62.6, \mathrm{df}=51, P=0.13$ ) or in Europe (Chi-squared $=74.1, \mathrm{df}=51, P=0.09$ ). However, $11.5 \%$ of the breeding raptors of Greece (Accipitriformes, Falconiformes) are found to be threatened (Chi-squared $=87.9, \mathrm{df}=51, P=0.001)$. 
Table 2. Top ten species with the highest increase and decrease in their population sizes in Greece along with their European trend and the European IUCN category of extinction risk. Values are presented as percent rate of change per year for years 1992 to 2014.

\begin{tabular}{|c|c|c|c|}
\hline Species & $\%$ rate of change in Greece (per year) & European trend & IUCN Europe \\
\hline \multicolumn{4}{|l|}{ Decreasing } \\
\hline Chlidonias hybrida & -5.1 & Increasing & LC \\
\hline Fringilla coelebs & $-4 \cdot 7$ & Stable & LC \\
\hline Acrocephalus melanopogon & $-4 \cdot 3$ & Unknown & $\mathrm{LC}$ \\
\hline Acrocephalus arundinaceus & -4.1 & Unknown & $\mathrm{LC}$ \\
\hline Neophron percnopterus & $-3 \cdot 9$ & Decreasing & EN \\
\hline Regulus regulus & -3.8 & Decreasing & LC \\
\hline Cyanistes caeruleus & -3.6 & Increasing & LC \\
\hline Emberiza melanocephala & $-3 \cdot 5$ & Decreasing & LC \\
\hline Chlidonias niger & $-3 \cdot 4$ & Unknown & LC \\
\hline Gallinula chloropus & -3.4 & Stable & LC \\
\hline \multicolumn{4}{|l|}{ Increasing } \\
\hline Streptopelia decaocto & 9.6 & Increasing & LC \\
\hline Apus pallidus & 8.7 & Stable & LC \\
\hline Cuculus canorus & 8.6 & Stable & $\mathrm{LC}$ \\
\hline Motacilla flava & 8.3 & Decreasing & LC \\
\hline Hydrobates pelagicus & 7.8 & Unknown & LC \\
\hline Cygnus olor & 6.5 & Increasing & $\mathrm{LC}$ \\
\hline Sturnus vulgaris & 6.1 & Decreasing & LC \\
\hline Bubulcus ibis & 6.0 & Decreasing & LC \\
\hline Sitta krueperi & 6.0 & Decreasing & LC \\
\hline Passer montanus & 5.8 & Uncertain & LC \\
\hline
\end{tabular}

Regarding ecological traits, and specifically habitat preferences (Figure S2), 152 of the 246 species breeding in Greece (61.8\%), require at least one broad habitat type (i.e. primary habitat). The Level One habitat type 'Forest' was the most frequent habitat type, listed as a primary habitat for $53(34.9 \%)$ species. Of these forest birds, $30.2 \%$ show a declining trend in the country, $41.5 \%$ are stable and $24.5 \%$ of them are increasing. Habitat type 'Wetland' was required by 31 species $(20.4 \%)$, with most of them showing an increasing trend $(48.4 \%)$, whereas a $25.8 \%$ of wetland species showed a stable and another $25.8 \%$ showed a decreasing trend. Of the 16 species (10.5\%) that require the habitat type 'Shrubland', most are either declining (37.5\%) or stable (37.5\%), with the remaining $25 \%$ exhibiting an increasing trend. Proportionally, there were no differences between species that require a specific habitat type and the trend direction, in Greece (Chi-squared $=41.3, \mathrm{df}=30, P=0.08$ ) or in Europe (Chi-squared $=32.2, \mathrm{df}=30, P=0.36$ ). There were no differences between the proportion of species assigned to a European Red List category concerning their primary habitat (Chi-squared $=13.8, \mathrm{df}=10, P=0.18$ ). For the majority of species breeding in Greece $(n=110,44.7 \%)$, invertebrates were the primary type of resource in their diets, followed by omnivores $(n=46,18.7 \%)$ and plant/seed eaters $(n=39,15.9 \%)$. The highest declines by dietary group were observed in scavengers, with three out of five species $(60 \%)$ showing a decreasing trend in Greece (Figure I). Proportionally, scavengers are indeed more likely to be in decline in Greece than species having other primary types of $\operatorname{diet}$ (Chi-squared $=26.6, \mathrm{df}=15, P=0.03$ ) although this does not seem to be the case in Europe (Chi-squared $=18.9, \mathrm{df}=15, P=0.22$ ). In addition, scavengers are more likely to be threatened (Chi-squared $=49.1, \mathrm{df}=15, P<0.001$ ), as this was the only dietary group where $40 \%$ of species are assigned to an IUCN threatened category.

The most common threat identified for birds breeding in Greece was 'Agriculture' ( $n=$ $114,46.3 \%)$, coded as having low impact for 45 species (39.5\%) and medium/high impact for $69(60.5 \%)$. 'Hunting and collecting' threatens 88 (35.8\%) species, having low impact and medium/high impact on $60(68.2 \%)$ and $28(31.8 \%)$ species, respectively. 'Pollution' is listed as a threat for the third largest number of species in Greece $(n=82,33.3 \%)$, impacting 49 of them 


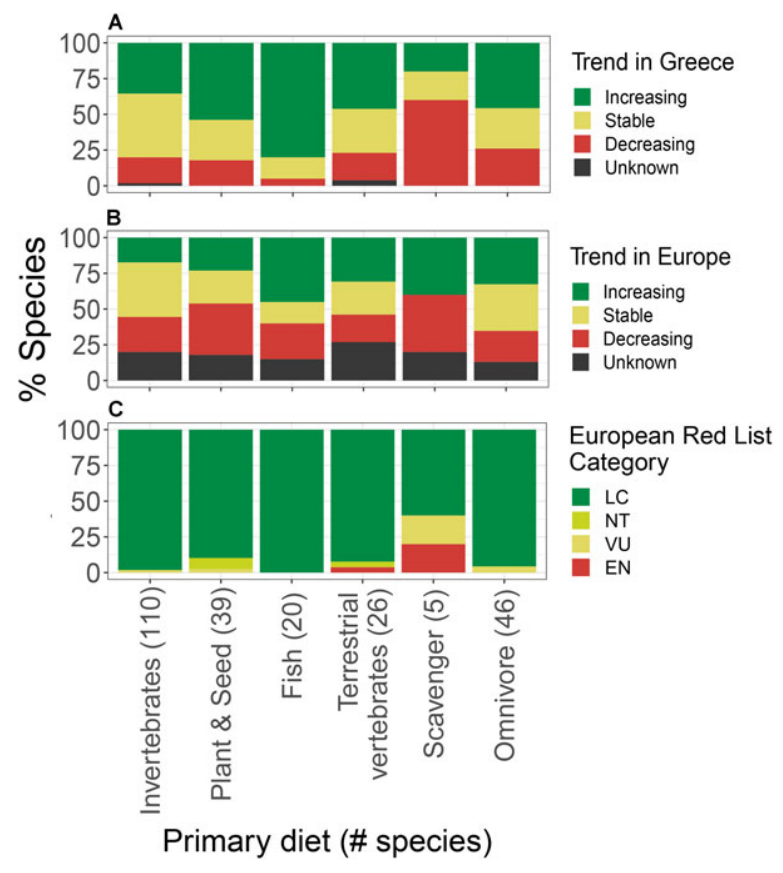

Figure 1. Percentages of species exhibiting different directions of population trends (Increasing, Decreasing, Stable, Unknown) in a) Greece and b) in Europe, and c) within different European IUCN Red List Categories (Endangered (EN), Vulnerable (VU), Near Threatened (NT) and Least Concern (LC)), for each dietary group. Number of species in each group is shown in brackets.

$(59.8 \%)$ on a low scale and $33(40.2 \%)$ on a medium/high scale (Figure 2 ). For the 46 species with a decreasing trend in Greece, 'Ecosystem modifications' including 'Dams and water management/ use' and 'Other ecosystem modifications', affect as a whole 29 species (63\%), having a medium/ high impact for eight of them (27.6\%). Agriculture was also a prominent threat, affecting 22 of the declining species $(47.8 \%), 12$ on a low scale and 10 on a medium/high scale. 'Pollution', 'Invasive species' and 'Hunting and collecting' threaten almost equal number of declining species $(17,17$, and 16 respectively; Figure 2).

Trigger species in each of the 204 IBAs of Greece ranged from one to 25 (mean of 4.4 trigger species per IBA). Sites with the highest trigger species richness $(>20)$ are major Ramsar Wetlands of International Importance located in western and northern Greece (GRo11, GRo12, GRo2O, GRo81). Seventy-one out of 204 IBAs (34.8\%) are triggered by at least one declining species. IBAs with the highest number of declining species (6) include one wetland in Northern Greece (Lake Kerkini; GRo2o) and two forest/lowland areas in Evros (north-eastern Greece; GRoo4, GRoo5) that are deemed of European importance for birds of prey (Figure 3; Hallmann 1985; Poirazidis et al. 2011). The three most frequently recommended conservation actions across species decreasing in Greece were 'Land and water management', 'Species management' and 'Law and policy', and they mainly refer to raptors and wetland species. Research recommendations emphasized the need to further elucidate the potential threats that affect the species declining in Greece (Figure 4).

\section{Discussion}

Our results indicate that almost one fifth of the breeding birds in Greece have declining populations. Among them, there are some cases where the population decline is well-documented such as 


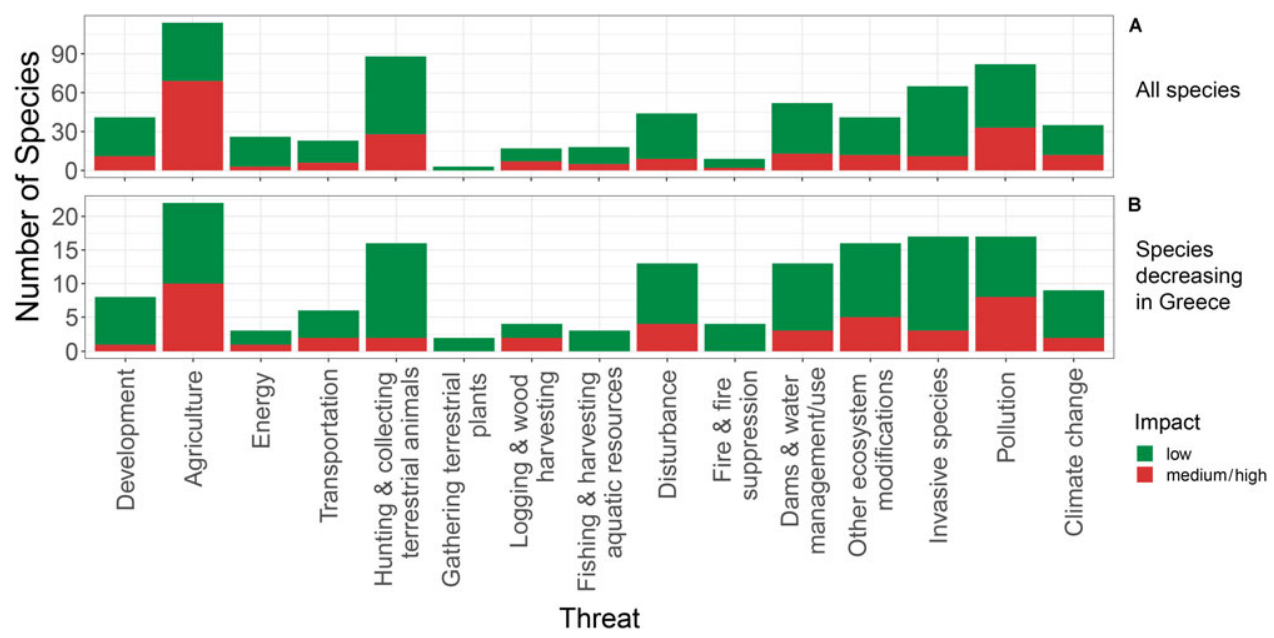

Figure 2. Number of species for which each threat class was listed for a) all species breeding in Greece and b) only for the species with decreasing trend. Threats are grouped by having low or medium/high impact.

A

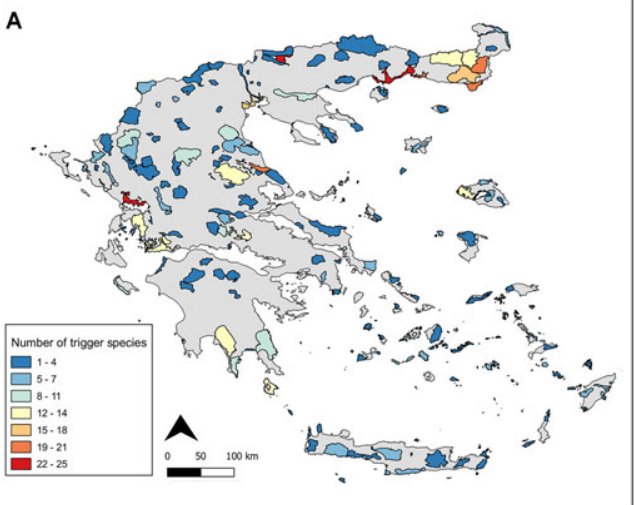

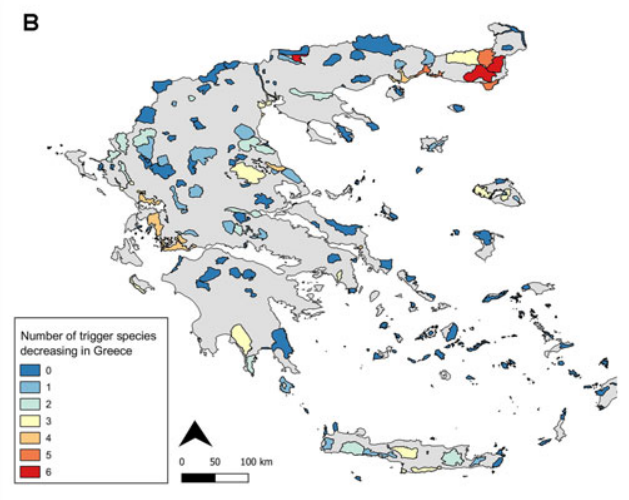

Figure 3. All 204 IBAs in Greece color coded according to a) trigger species richness and b) number of trigger species with decreasing trends.

the Whiskered Tern and Black Tern Chlidonias niger. Both species depend on floating vegetation for nesting (Paillisson et al. 2006) and have been breeding in Lake Kerkini, north-western Greece, benefitted from hydrological changes that resulted in the appearance of an extensive bed of white water lilies Nymphaea alba after 1982 (Crivelli et al. 1995). When the water lily bed almost disappeared (Manou and Papathanasiou 2009), the number of breeding pairs dropped almost to zero (Legakis and Maragou 2009). Moreover, the Egyptian Vulture population has suffered steep declines not only in Greece but throughout the Balkan Peninsula. In the last 30 years, the range of the species has decreased considerably and its populations have suffered a steep decrease of $80 \%$, at an estimated rate of $4-8 \%$ per year (Velevski et al. 2015), a value consistent with the rate of $3.9 \%$ we report in this study for the last 20 years. However, some other declines are much more challenging to interpret; some common passerine species such as the Chaffinch Fringilla coelebs and the Moustached and Great Reed warblers were found to show alarming rates of decline in the 

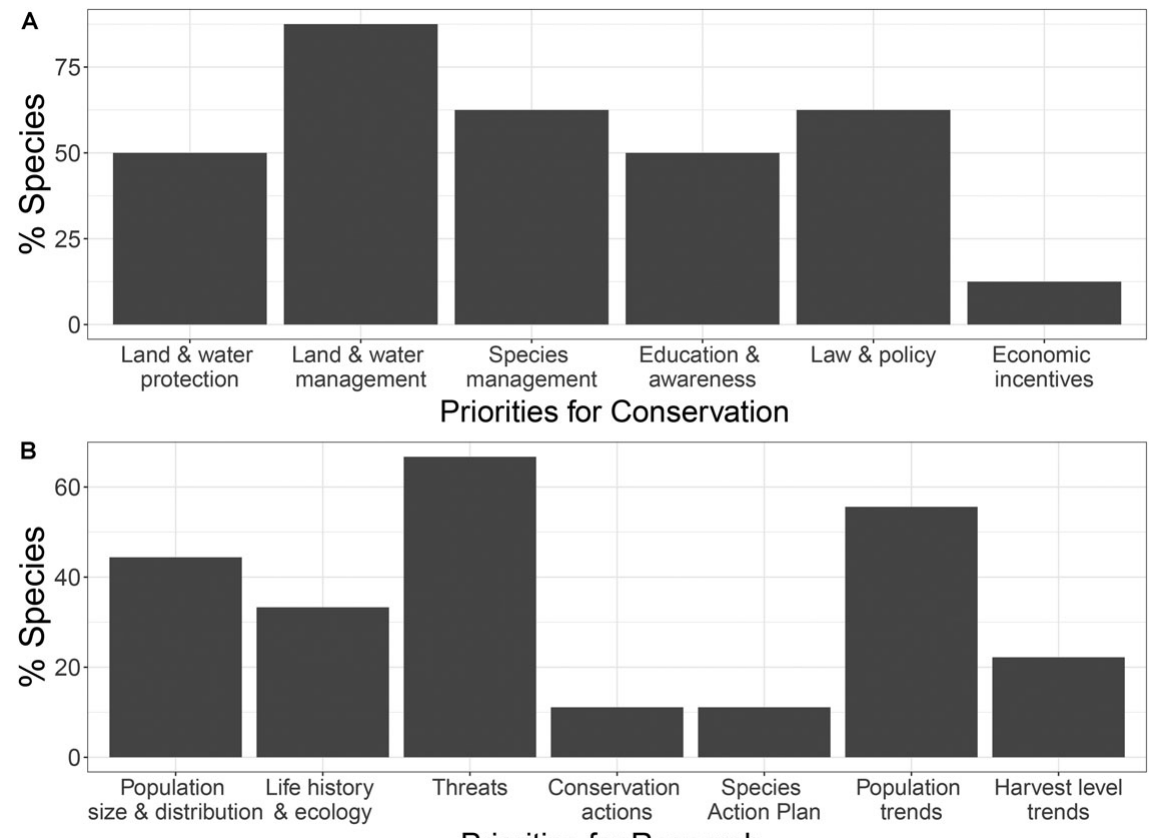

Priorities for Research

Figure 4. Priorities for a) conservation actions and b) research recommended for the declining breeding birds of Greece as listed by IUCN.

country. Monitoring passerine populations requires long-term schemes and even then, estimations are susceptible to bias due to a variety of factors (Nichols et al. 2009). Thus, these results could very well be an artefact of the dataset heterogeneity (as mentioned in the methods section). However, it has been proposed that European common birds show rapid declines in contrast to less abundant ones (Inger et al. 2015) and therefore our results should be kept in mind as such species may be in need of special attention in the future. In fact, the trends of the two warbler species are considered overall stable in neighbouring countries (e.g. Bulgaria; Iankov 2007), however a suspected declining trend for the Great Reed Warbler has been indicated (Dyrcz 2020). On the other hand, species showing the greatest increase include one that is regarded as invasive. The Collared Dove has progressively occupied almost all Greek territory since the beginning of the $20^{\text {th }}$ century (Handrinos and Akriotis 1997), whilst such a pattern is documented throughout Europe with colonization of new areas (Hengeveld and Vandenbosch 1991) and even its expansion as an invasive species in North America (Sauer et al. 2017). Similarly, the Cattle Egret which was not breeding in Greece until 1991 (Goutner et al. 1991) has since showed remarkable increase in its population size. Such an expansion is reported from other areas too, e.g. from Italy (Nunes et al. 2010) and Algeria (Si Bachir et al. 2011). The Rook, which was considered a sporadic breeder in the country, showed a tremendous increase since 1992. Interestingly, similar patterns were observed in the UK, with an increase of $40 \%$ in 20 years (Marchant and Gregory 1999) and in Germany where the population of the species decreased substantially by 1976 and subsequently increased by $86.4 \%$ of its initial size until 2017, following the placement of the species' conservation status under protection in 1977 (Krüger et al. 2020). Finally, regarding the case of the European Storm-petrel Hydrobates pelagicus, the significant increase reported herein, reflects the intensified research efforts on seabirds that took place in Greece during the last decade and led to the discovery of new breeding colonies (Fric et al. 2012) or to more accurate estimates of known breeding. In fact, the species' trend in Europe is considered "Unknown" (BirdLife International 2015) further reflecting the uncertainty 
in monitoring efforts of the species, and data on European Storm-petrel abundance should be treated with caution (de León et al. 2006).

When examining species at the taxonomic level, although our results showed no disproportionate declines between orders, they indicated that the breeding raptors of Greece constitute the most threatened group. This is further elucidated by the analysis of ecological traits and specifically the primary diet of each species, with scavengers being proportionally the most declining group of birds in Greece. The fact that raptor species in Greece are in decline was realised in the 1980s (Hallmann 1985) with the main causes including habitat loss and shooting. Today both these threats persist; shooting is the main cause of admission of raptors to wildlife rehabilitation centres (Mazaris et al. 2008) while habitat loss mostly relates to ongoing development plans and accompanying infrastructure, which can have a tremendous effect on raptor populations, especially if such plans are implemented inappropriately (Carrete et al. 2009, Vasilakis et al. 2017). Furthermore, additional threats become more and more evident. Currently, illegal poisoning is now considered as one of the leading threats to raptor species, threatening their populations at a national level (Ntemiri et al. 2018) and triggering scavenger declines and local extinctions throughout the country (Xirouchakis et al. 2001, Skartsi et al. 2008). Raptor declines are not limited to Greece but are currently a global phenomenon. Despite their value and role in providing critical ecosystem services (Gaston et al. 2018) this is the most threatened group of birds in the world (Buechley and Şekercioğlu 2016, McClure et al. 2018). This is rather alarming as top predators have been linked to higher levels of biodiversity and thus their preservation should be prioritized and enable ecosystem-level conservation and broader biodiversity benefits (Sergio et al. 2006).

According to IUCN Red List assessments, agriculture was identified as the most frequent threat for the breeding birds in Greece, both for all species and for species with declining trends. Population declines of farmland birds have become a major conservation concern throughout Europe (Tucker and Heath 1994, Gregory et al. 2004) and have been driven by land-use changes and agricultural intensification as enforced by the Common Agricultural Policy (CAP) (Donald et al. 2002, Busch et al. 2020). The severity of farmland bird declines is further reflected by a $>50 \%$ reduction of the EU farmland bird indicators since 1980 (Gregory et al. 2005, EBCC 2017). Although our results suggest that currently there are no disproportionate habitat-related declines regarding farmland birds in Greece, policies such as the CAP act at large spatial scales and can have tremendous impact on bird populations over extended geographic areas. Therefore, future implementation of management practices, to either prevent farmland bird declines or to restore agricultural landscapes, should largely focus on efficient tuning of the CAP and a possible reorientation towards environmental sustainability and thus effectively facilitate biodiversity conservation (Pe'er et al. 2019). Unsurprisingly, natural system modifications, including dams and water management as well as pollution (that encompasses discharges with fertilizer and pesticide residues), ranked among the most frequent threats and are mainly linked to abovementioned agricultural practices. The threat category "Hunting and collecting terrestrial animals" was the second most important threat identified in this study. We should note that species could actually be affected by a wide range of different threats encompassed in this category as it consists of heterogeneous threat types including intentional events for subsistence, sport or direct persecution along with any unintentional resulting mortality, such as poisoning. The category includes both legal and illegal hunting (Salafsky et al. 2008). Despite the obvious pressure that direct actions such as hunting/illegal hunting can have on both resident and migratory bird populations (Gross 2015), there are many subtle effects that are included in this category, such as lead poisoning. Poisoning from lead shot in waterfowl has been well documented (Mateo 2009) but there is increasing evidence that terrestrial species such as raptors and game birds are also affected by exposure to high levels of lead through spent hunting ammunition (Fisher et al. 2006). In Greece, lead ingestion by waterfowl has been documented since the 1990s (Pain and Handrinos 1990), whereas recently lead poisoning was found to be an additional pressure on the Egyptian Vulture (Bounas et al. 2016), a species that, as we have already mentioned, shows one of the sharpest rates of decline in the country and is listed as globally 'Endangered'. The threat posed by invasive species has a low impact 
on most species but affects all seabirds in Greece. Invasive species, and specifically rats Rattus spp., are believed to be one of the primary threats to nesting seabirds (Croxall et al. 2012) and global efforts on their eradication have proved to be substantially beneficial (Jones et al. 2016). In Greece, several actions on rat eradication have been implemented to safeguard seabird breeding grounds and have resulted to substantial conservation gains (Fric et al. 2012).

Given that threats causing habitat alteration and degradation are the most important for the breeding birds of Greece, "Land and Water Management" outranks the rest of the recommended conservation actions. However, except for restoring habitats and ecosystem functions, this category also encompasses the management of protected areas (Salafsky et al. 2008). Although wetland IBAs seem to hold the highest number of trigger species, contrastingly, the highest number of declining trigger species is observed in the lowland areas of Thrace, north-eastern Greece. This is rather unsurprising due to the fact that the Evros area is a stronghold for raptor populations and is characterised by one of the most diverse arrays of breeding raptor species in Europe (Hallmann 1985, Poirazidis et al. 2011). Therefore, adequate protection of such areas of international importance is necessary and development plans that could lead to habitat loss and degradation should be discouraged. In addition, priority conservation actions should be implemented in order to safeguard the future of raptor populations. Given the threat posed to raptors by poisoning, it is logical that the most frequently recommended conservation actions within Red List assessments for the breeding birds of Greece are "Species management", "Education and Awareness" as well as development and enforcement regarding "Law and Policy". Improvement of legislation is the action that currently could most likely make a difference; law enforcement and the establishment of a clear legal framework laying out the responsibilities of authorities involved is a priority issue in order to tackle the illegal use of poison bait in Greece (Ntemiri et al. 2018). Improved regulation regarding the use of poisons and lead ammunition, mitigation of the risk of electrocution/collision on dangerous powerlines, and the sensible spatial planning of wind farms to minimize conservation costs (Vasilakis et al. 2017), could help prevent the accelerated anthropogenic mortality of bird species.

To be efficient, conservation actions they need to be informed by further research. Our results suggest that specific drivers of change have to be identified along with examination of current and past population trends. Indeed, ornithological research in Greece since the $1980 \mathrm{os}$ has focused on the increase of knowledge regarding the distribution, numbers and status of many bird species as well as their breeding ecology. However, studies that deal with population monitoring and effects of different factors on bird populations were rather rare in the past although they have recently been increasing (Kazantzidis 2007). Standardized bird monitoring efforts can subsequently lead to a more rapid response in addressing any drivers of population decline and thus further increase the strength and accuracy of Red List Assessments. Eleven years have passed since the publication of the Red Data Book of Greece (Legakis and Maragou 2009), and this study further corroborates the imperative need to update the Red Data Book and include more species in its assessments, especially of breeding species for which the country bears the greatest responsibility.

\section{Supplementary Materials}

To view supplementary material for this article, please visit http://dx.doi.org/10.1017/ So959270920000568.

\section{Acknowledgements}

We are thankful to Tom Matthews, Danae Portolou and two anonymous reviewers for providing valuable comments on previous drafts of this manuscript. 


\section{References}

Barnosky, A. D., Matzke, N., Tomiya, S., Wogan, G. O., Swartz, B., Quental, T. B., Marshall, C., McGuire, J. L., Lindsey, E. L. and Maguire, K. C. (2011) Has the Earth's sixth mass extinction already arrived? Nature 471: 51-57.

BirdLife International (2004) Birds in Europe: population estimates, trends and conservation status. Cambridge, UK: BirdLife International.

BirdLife International (2014) Important Bird and Biodiversity Areas: A global network for conserving nature and benefiting people. Cambridge, UK: BirdLife International.

BirdLife International (2015) European red list of birds. Luxembourg: Office for Official Publications of the European Communities. BirdLife International (2017) European birds of conservation concern: populations, trends and national responsibilities. Cambridge, UK: BirdLife International.

Bounas, A., Ganoti, M., Giannakaki, E., Akrivos, A., Vavylis, D., Zorrilla, I. and Saravia, V. (2016) First confirmed case of lead poisoning in the endangered Egyptian Vulture (Neophron percnopterus) in the Balkans. Vulture News 70: 22-29.

Bounas, A., Catsadorakis, G., Logotheti, A., Voslamber, B., Magoulas, A. and Tsaparis, D. (2018) Conservation genetics of a resident population of Greylag Goose (Anser anser) at the southernmost limit of the species' distribution in Europe. Avian Res. 9: 47.

Brouwer, J., Baker, N. and Trolliet, B. (2003) Estimating bird population size and trends: what are the hard data, what are the unavoidable assumptions? A plea for good documentation. Wader Study Group Bull. 100: 197-201.

Buechley, E. R. and Şekercioğlu, Ç. H. (2016) The avian scavenger crisis: Looming extinctions, trophic cascades, and loss of critical ecosystem functions. Biol. Conserv. 198: 220-228.

Busch, M., Katzenberger, J., Trautmann, S., Gerlach, B., Dröschmeister, R. and Sudfeldt, C. (2020) Drivers of population change in common farmland birds in Germany. Bird Conserv. Internatn. 30: 335-354.

Butchart, S. H., Stattersfield, A. J., Bennun, L. A., Shutes, S. M., Akçakaya, H. R., Baillie,
J. E., Stuart, S. N., Hilton-Taylor, C. and Mace, G. M. (2004) Measuring global trends in the status of biodiversity: Red List Indices for birds. PLoS Biology 2: ez83.

Butchart, S. H., Walpole, M., Collen, B., Van Strien, A., Scharlemann, J. P., Almond, R. E., Baillie, J. E., Bomhard, B., Brown, C. and Bruno, J. (2010) Global biodiversity: indicators of recent declines. Science 328: 1164-1168.

Carrete, M., Sánchez-Zapata, J. A., Benítez, J. R., Lobón, M. and Donázar, J. A. (2009) Large scale risk-assessment of wind-farms on population viability of a globally endangered long-lived raptor. Biol. Conserv. 142: 2954-2961.

Catsadorakis, G., Avramoski, O., Bojadzi, A. and Nikolaou, H. (2016) The status of an isolated population of Goosander Mergus merganser in the Balkans. Wildfowl 66: 159-175.

Ceballos, G., Ehrlich, P. R. and Dirzo, R. (2017) Biological annihilation via the ongoing sixth mass extinction signaled by vertebrate population losses and declines. Proc. Natil. Ac. Sci. 114: E6089-E6o96.

Crivelli, A., Grillas, P. and Lacaze, B. (1995) Responses of vegetation to a rise in water level at Kerkini Reservoir (1982-1991), a Ramsar site in northern Greece. Environ. Manage. 19: 417-430.

Croxall, J. P., Butchart, S. H., Lascelles, B., Stattersfield, A. J., Sullivan, B., Symes, A. and Taylor, P. (2012) Seabird conservation status, threats and priority actions: a global assessment. Bird Conserv. Internatn. 22: 1-34. de León, A., Mínguez, E., Harvey, P., Meek, E., Crane, J. E. and Furness, R. W. (2006) Factors affecting breeding distribution of Storm-petrels Hydrobates pelagicus in Orkney and Shetland. Bird Study 53: 64-72. Dimalexis, A., Xirouchakis, S., Portolou, D., Latsoudis, P., Karris, G., Fric, J., Georgiakakis, P., Barboutis, C., Bourdakis, S., Ivovič, M., Kominos, T. and Kakalis, E. (2008) The status of Eleonora's Falcon (Falco eleonorae) in Greece. .J. Ornithol. 149: 23-30.

Donald, P. F., Pisano, G., Rayment, M. D. and Pain, D. J. (2002) The Common Agricultural Policy, EU enlargement and the conservation 
of Europe's farmland birds. Agric. Ecosys. Environ. 89: 167-182.

Dyrcz, A. (2020) Great Reed Warbler (Acrocephalus arundinaceus), version 1.o. In J. del Hoyo, A. Elliott, J. Sargatal, D. A. Christie, and E. de Juana, eds. Birds of the World. Ithaca, NY, USA: Cornell Lab of Ornithology. https://doi.org/10.2173/bow. grrwari.oI

EBCC (European Bird Census Council) (2017) European wild bird indicators, 2017 update. http://www.ebcc.info/european-wild-birdindicators-2017-update/. Accessed 28 May $2 \mathrm{O} 2 \mathrm{O}$.

Fisher, I. J., Pain, D. J. and Thomas, V. G. (2006) A review of lead poisoning from ammunition sources in terrestrial birds. Biol. Conserv. 131: 421-432.

Fric, J., Trigou, R., Dendrinos, P., Karris, G., Peristeraki, P., Kasapidis, P., Ramirez, I. and Dimalexis, T. (2012). Conservation actions for the Mediterranean Shag Phalacrocorax aristotelis desmarestii and Audouin's Gull Larus audouinii in Greece, including the inventory of relevant marine IBAs. Pp. 223-228 in P. Yesou, N. Baccetti and J. Sultana, eds. Ecology and conservation of Mediterranean seabirds and other bird species under the Barcelona Convention-Proceedings of the 13 th Medmaravis Pan-Mediterranean Symposium. Alghero, Sardinia: Medmaravis.

Gaston, K. J., Cox, D. T., Canavelli, S. B., García, D., Hughes, B., Maas, B., Martínez, D., Ogada, D. and Inger, R. (2018) Population abundance and ecosystem service provision: The case of birds. Bioscience 68: 264-272.

Goutner, V., Jerrentrup, H., Kazantzidis, S. and Nazirides, T. (1991) Occurrence of the cattle egret, Bubulcus ibis, in Greece. Riv. Ital. Ornitol. 61: 107-112.

Gregory, R. D., Noble, D. G. and Custance, J. (2004) The state of play of farmland birds: population trends and conservation status of lowland farmland birds in the United Kingdom. Ibis 146: 1-13.

Gregory, R. D., Van Strien, A., Voříšek, P., Gmelig Meyling, A. W., Noble, D. G., Foppen, R. P. and Gibbons, D. W. (2005) Developing indicators for European birds. Phil. Trans. Roy. Soc. B: Biol. Sci. 360: 269-288.

Gross, M. (2015) Europe's bird populations in decline. Curr. Biol. 25: R483-R485.
Hallmann, B. (1985) Status and conservation problems of birds of prey in Greece. Pp. 5559 in Conservation studies on raptors. Cambridge, UK: International Council fvor Bird Preservation. (ICBP Technical Publication 5).

Handrinos, G. and Akriotis, T. (1997) The birds of Greece. London, UK: Christopher Helm.

Hengeveld, R. and Vandenbosch, F. (1991) The expansion velocity of the Collared dove Streptopelia decaocto population in Europe. Ardea 79: 67-72.

Iankov, P. (2007) Atlas of breeding birds in Bulgaria. Sofia: Bulgarian society for the protection of birds.

Inger, R., Gregory, R., Duffy, J. P., Stott, I., Voříšek, P. and Gaston, K. J. (2015) Common European birds are declining rapidly while less abundant species' numbers are rising. Ecol. Lett. 18: 28-36.

Jones, H. P., Holmes, N. D., Butchart, S. H., Tershy, B. R., Kappes, P. J., Corkery, I., Aguirre-Muñoz, A., Armstrong, D. P., Bonnaud, E. and Burbidge, A. A. (2016) Invasive mammal eradication on islands results in substantial conservation gains. Proc. Natl. Ac. Sci. 113: 4033-4038.

Karandinos, M. and Paraschi, L. (1992) The red data book of threatened vertebrates of Greece. Athens, Greece: Hellenic Zoological Society \& Hellenic Ornithological Society.

Kati, V., Devillers, P., Dufrêne, M., Legakis, A., Vokou, D. and Lebrun, P. (2004) Testing the value of six taxonomic groups as biodiversity indicators at a local scale. Conserv. Biol. 18: 667-675.

Kazantzidis, S. (2007) Trends in current ornithology in Greece. J. Biol. Research -Thessaloniki 8: 139-149.

Kazantzidis, S., Portolou, D. and Yfantis, G. (2016) Changes in size and distribution of heron colonies during the period 2003-2014 in Greece. In: Proceedings of the 8th Congress of the Hellenic Ecological Society, Thessaloniki, Greece.

Kleinbaum, D. G., Kupper, L. L., Nizam, A. and Rosenberg, E. S. (2013) Applied regression analysis and other multivariable methods. Torontyo, Canada: Nelson Education.

Krüger, T., Heckenroth, H., Prior, N., Seitz, J. and Zang, H. (2020) Persecution and statutory protection have driven Rook Corvus frugilegus population dynamics over the 
past 120 years in NW-Germany. J. Ornithol. 161: 569-584.

Legakis, A. and Maragou, P. (2009) The Red Data Book of the threatened animals of Greece. Athens: Hellenic Zoological Society.

Mace, G. M. and Baillie, J. E. (2007) The 2010 biodiversity indicators: challenges for science and policy. Conserv. Biol. 21: 1406-1413.

Manou, D. and Papathanasiou, J. (2009) Exploring the potential failure of the regulatory framework and management tools which govern the conservation of biodiversity: the case of artificial Lake Kerkini in Greece. J. Environ. Assess. Pol. Manage. 11: 213-243.

Marchant, J. H. and Gregory, R. D. (1999) Numbers of nesting Rooks Corvus frugilegus in the United Kingdom in 1996. Bird Study 46: 258-273.

Mateo, R. (2009) Lead poisoning in wild birds in Europe and the regulations adopted by different countries. Pp. 78-91 in R. T. Watson, M. Fuller, M. Pokras and W. G. Hunt, eds. Ingestion of lead from spent ammunition: Implications for wildlife and humans. Boise, Idaho: The Peregrine Fund.

Mazaris, A. D., Mamakis, Y., Kalpakis, S., Poulopoulos, Y. and Matsinos, Y. G. (2008) Evaluating potential threats to birds in Greece: an analysis of a 10-year data set from a rehabilitation centre. Oryx 42: 408-414.

McClure, C. J., Westrip, J. R., Johnson, J. A., Schulwitz, S. E., Virani, M. Z., Davies, R., Symes, A., Wheatley, H., Thorstrom, R., Amar, A., Buij, R., Jones, V. R., Williams, N. P., Buechley, E. R. and Butchart, S. H. (2018) State of the world's raptors: Distributions, threats, and conservation recommendations. Biol. Conserv. 227: 390-402.

Nichols, J. D., Thomas, L. and Conn, P. B. (2009) Inferences About landbird abundance from count data: Recent advances and future directions. Pp. 201-235 in D. L. Thomson, E. G. Cooch and M. J. Conroy, eds. Modeling demographic processes in marked populations. Boston, MA: Springer.

Ntemiri, K., Saravia, V., Angelidis, C., Baxevani, K., Probonas, M., Kret, E., Mertzanis, Y., Iliopoulos, Y., Georgiadis, L., Skartsi, D., Vavylis, D., Manolopoulos, A., Michalopoulou, P. and Xirouchakis, S.M. (2018) Animal mortality and illegal poison bait use in Greece. Environ. Monit. Assess. 190: 488.
Nunes, M. F. C., Barbosa-Filho, R. C., Roos, A. L. and Mestre, L. A. M. (2010) The Cattle Egret (Bubulcus ibis) on Fernando de Noronha Archipelago: history and population trends. Rev. Brasil. Ornitol. 18: 315-327.

Paillisson, J.-M., Reeber, S., Carpentier, A. and Marion, L. (2006) Plant-water regime management in a wetland: consequences for a floating vegetation-nesting bird, whiskered tern Chlidonias hybridus. Biodivers. Conserv. 15: 3469-3480.

Pain, D. J. and Handrinos, G. (1990) The incidence of ingested lead shot in ducks of the Evros Delta, Greece. Wildfowl 41: 167-170.

Pe'er, G., Zinngrebe, Y., Moreira, F., Sirami, C., Schindler, S., Müller, R., Bontzorlos, V., Clough, D., Bezák, P., Bonn, A., Hansjürgens, B., Lomba, A., Möckel, S., Passoni, G., Schleyer, C., Schmidt, J. and Lakner, S. (2019) A greener path for the EU Common Agricultural Policy. Science 365: 449-451.

Pigot, A. L., Trisos, C. H. and Tobias, J. A. (2016) Functional traits reveal the expansion and packing of ecological niche space underlying an elevational diversity gradient in passerine birds. Proc. Roy. Soc. B: Biol. Sci. 283: 20152013.

Poirazidis, K., Schindler, S., Kakalis, E., Ruiz, C., Bakaloudis, D. E., Scandolara, C., Eastham, C., Hristov, H. and Catsadorakis, G. (2011) Population estimates for the diverse raptor assemblage of Dadia National Park, Greece. Ardeola 58: 3-17.

Portolou, D., Bourdakis, S., Vlachos, C., Kastritis, T. and Dimalexis, T. (2009) The important bird areas of Greece: priority areas for biodiversity conservation. Athens: Hellenic Ornithological Society.

QGIS Core Team (2016) QGIS Geographic Information System. Open Source Geospatial Foundation Project. http://qgis.osgeo. org

R Core Team (2019) R: A language and environment for statistical computing. Vienna, Austria: R Foundation for Statistical Computing. http://www.r-project.org/

Rodrigues, A. S., Pilgrim, J. D., Lamoreux, J. F., Hoffmann, M. and Brooks, T. M. (2006) The value of the IUCN Red List for conservation. Trends Ecol. Evol. 21: 71-76.

Rosenberg, K. V., Dokter, A. M., Blancher, P. J., Sauer, J. R., Smith, A. C., Smith, P. A., 
Stanton, J. C., Panjabi, A., Helft, L. and Parr, M. (2019) Decline of the North American avifauna. Science 366: 120-124.

Salafsky, N., Salzer, D., Stattersfield, A. J., HiltonTaylor, C., Neugarten, R., Butchart, S. H., Collen, B., Cox, N., Master, L. L. and O'Connor, S. (2008) A standard lexicon for biodiversity conservation: unified classifications of threats and actions. Conserv. Biol. 22: 897-911.

Sauer, J. R., Pardieck, K. L., Ziolkowski Jr, D. J., Smith, A. C., Hudson, M.-A. R., Rodriguez, V., Berlanga, H., Niven, D. K. and Link, W. A. (2017) The first 50 years of the North American breeding bird survey. The Condor: Ornithol. Applic. 119: 576-593.

Schielzeth, H. (2010) Simple means to improve the interpretability of regression coefficients. Meth. Ecol. Evol. 1: 103-113.

Şekercioğlu, Ç. H., Daily, G. C. and Ehrlich, P. R. (2004) Ecosystem consequences of bird declines. Proc. Natl. Ac. Sci. 101: 18042-18047.

Sergio, F., Newton, I., Marchesi, L. and Pedrini, P. (2006) Ecologically justified charisma: preservation of top predators delivers biodiversity conservation. J. Appl. Ecol. 43: 1049-1055.

Si Bachir, A., Ferrah, F., Barbraud, C., Céréghino, R. and Santoul, F. (2011) The recent expansion of an avian invasive species (the Cattle Egret Ardea ibis) in Algeria. J. Arid Environ. 75: 1232-1236.

Skartsi, T., Elorriaga, J. N., Vasilakis, D. P. and Poirazidis, K. (2008) Population size, breeding rates and conservation status of Eurasian black vulture in the Dadia National Park, Thrace, NE Greece. J. Nat. Hist. 42: 345-353.

Sutherland, W. J., Newton, I. and Green, R. (2004) Bird ecology and conservation: A handbook of Techniques. Oxford, UK: Oxford University Press.
Tucker, G. M. and Heath, M. F. (1994) Birds in Europe: their conservation status. Cambridge, UK: BirdLife International.

van Strien, A. J., Pannekoek, J. and Gibbons, D. W. (2001) Indexing European bird population trends using results of national monitoring schemes: a trial of a new method. Bird Study 48: 200-213.

Vasilakis, D. P., Whitfield, D. P. and Kati, V. (2017) A balanced solution to the cumulative threat of industrialized wind farm development on cinereous vultures (Aegypius monachus) in south-eastern Europe. PLOS ONE 12(2): eo172685. https://doi. org/I0.1371/journal.pone.0172685.

Velevski, M., Nikolov, S. C., Hallmann, B., Dobrev, V., Sidiropoulos, L., Saravia, V., Tsiakiris, R., Arkumarev, V., Galanaki, A., Kominos, T., Stara, K., Kret, E., Grubac, B., Lisicanec, E., Kastritis T., Vavylis, D., Topi, M., Hoxha, B. and Oppel, S. (2015) Population decline and range contraction of the Egyptian Vulture Neophron percnopterus in the Balkan Peninsula. Bird Conserv. Internatn. 25: 440-450.

Vorisek, P., Gregory, R. D., Van Strien, A. J. and Meyling, A. G. (2008) Population trends of 48 common terrestrial bird species in Europe: results from the Pan-European Common Bird Monitoring Scheme. Rev. Catalana Ornitol. 24: 4-14.

Wilman, H., Belmaker, J., Simpson, J., De La Rosa, C., Rivadeneira, M. M. and Jetz, W. (2014) EltonTraits 1.o: Species-level foraging attributes of the world's birds and mammals. Ecology 95: 2027-2027.

Xirouchakis, S., Sakoulis, A. and Andreou, G. (2001) The decline of the Bearded Vulture Gypaetus barbatus in Greece. Ardeola 48: 183-190. 